\title{
Regular Daily Ablution (Wudu') Consequence on Reduction Coronavirus Infection during Pandemic in Saudi Society
}

\author{
Sherifa Mostafa M. Sabra*1 and Afaf Bushara M. Ismail ${ }^{2}$ \\ ${ }^{1}$ Technology and Science Dept., Ranyah University C., Taif U., KSA \\ ${ }^{2}$ Food and Nutrition Dept., Science C., Hawiah, Taif U., KSA
}

*Corresponding Author: Sherifa Mostafa M. Sabra, Technology and Science Dept., Ranyah University C., Taif U., KSA

Received date: August 21, 2021: Accepted date: September 10, 2021: Published date: September 28,2021

Citation: Sherifa M. M. Sabra B. M. Ismail, (2021). Regular Daily Ablution (Wudu') Consequence on Reduction Coronavirus Infection during Pandemic in Saudi SocietyJ. of Clin Case Rep and Stu 3(6); DOI: 10.31579/2690-8808/089

Copyright: (C) 2021 Sherifa Mostafa M. Sabra, This is an open access article distributed under the Creative Commons Attribution License, which permits unrestricted use, distribution, and reproduction in any medium, provided the original work is properly cited.

\begin{abstract}
Prophet Muhammad (peace be upon Him) said: "Cleanliness is half of faith", protect from infectious disease. Coronavirus infection prevention closely related to Muslims advice as regular daily ablution (Wudu'). The aim was for Moslem individuals to follow regular daily ablution (Wudu'), its impact on health protection of individual and Saudi society from infectious diseases and Coronavirus during pandemic. That was used the "Study Competency" and the "Coupled Assessment" was utilized "Reaching Study Question Consequences", the "Moderate Excel Packet" was outcome defined. The results were forfirst question "Perform regular daily ablution for prayer"; was $100 \%$. The second question "Urges an individuals to perform regular daily ablution"; was $97 \%$. stionThe third que "Regular daily ablution helps to clean the body organs well"; was 92\%. The fourth question"Regular daily ablution is one of the ways to sterilize with running water"; was $81 \%$. The fifth question"Regular daily ablution is improved an individual health status"; was $80 \%$. The sixth question "Regular daily ablution helps to reduce an individual pathogenic microorganisms infection"; was $81 \%$. The seventh question "Regular daily ablution is one of the ways to protect an easesindividual health from microbial dis"; was $86 \%$. The eighth question "Regular daily ablution helps the success of "Health Precautionary Measures" to prevent Coronavirus infection" was $82 \%$. The ninth question "Regular daily nablution health way to reduces an individual Coronavirus infectio"; was $86 \%$. The tenth question"Regular daily ablution healthy ways to reduce and protect Saudi society from Coronavirus infection"; was $84 \%$. It was concluded that through the results to the extent of the strength of Islam for the Saudi society and the strength of implementing the provisions of Islam for the individual and Saudi society. Regular daily ablution (Wudu') consequence had proven strengthen the health of the individual and Saudi society and reduce infectious microbial diseases. The individual from Saudi society, and when observing regular daily ablution (Wudu') and updating ablution (Wudu') reduce and protect from Coronavirus infection during pandemic. That beneficial to individual health and Saudi society health. It was recommend that the commitment to implement the Islamic steps as regular daily ablution (Wudu') reduces infectious microbial diseases, reduces and protects individuals and Saudi society from Coronavirus infection during pandemic.

Key words: coronavirus infection, regular daily ablution (Wudu'), moslem individuals, saudi society, infectious diseases, pandemic
\end{abstract}

\section{Introduction}

Regular Daily Ablution (Wudu') and prayer have health benefits and it is a direct connection with Allah. Prophet Muhammad (peace be upon Him) said: "Cleanliness is half of faith", that protect ourselves from the infectious disease [1]. Regular daily ablution (Wudu') is an Arabic word means the specific action of washing certain body parts has importance. Muslims are perform regular daily ablution (Wudu') before prayer five times per day. As well pathogenic microorganisms can enter in the body through mouth, nose and eyes directly or indirectly from contaminated hands and foots. So regular daily ablution (Wudu') significantly reduce different infections microorganisms roles from oral cavity infections, intestinal infections, skin and eyes, respiratory infections. That including present pandemic Coronavirus as "breaking the chain of transmission". Personal hygiene is one of the important practices in breaking the chain, in Islam it has been ordered in Quran and Hadith. Regular daily ablution (Wudu') five times per day provide good hygiene and prevent the microbial infections. Therefore it is educate people about the importance and basic steps of regular daily ablution (Wudu') for great personal hygiene [2]. Prophet Muhammad (peace be upon Him) introduced the 
quarantining and hygiene practice as regular daily ablution (Wudu') to combat the infection diseases and also now and then prevent the Coronavirus infection spread, that connected with an Islamic managing [3]. Meanwhile, water penetration into the nasal cavity and out during regular daily ablution (Wudu') corresponds to the nasal rinse and gargling methods, which prevents the mechanical and chemical attachment of Coronavirus. So Islamic-based nasal rinse and gargling help Coronavirus infection prevention [4]. Coronavirus infection prevention are currently closely related to the advice of Muslims against hygiene orders. Various efforts are currently being made by all governments in the world for preventing and breaking the chain of distribution of Coronavirus infection including WHO. That motivated to prevent the Coronavirus infection spread from the teachings of Islam. That was Coronavirus prevention protocol policy and its relationship on regular daily ablution (Wudu') as an prevention effort in Government policies and various institutions. So, regular daily ablution (Wudu') as a disciplinary activity for Muslims emphasis on clean and healthy lifestyle in preventive Coronavirus infection efforts [5].

The aim of the current research was for Moslem individuals to follow up on performing regular daily ablution (Wudu') and adhere to it. Also the extent of its impact on the health protection of the individual and Saudi society from infectious microbial diseases. As well as to reduce and protect the individual and Saudi society from infection with the Coronavirus during the pandemic.

\section{Methodology}

The "Study Competency" was utilized on the Muslim individual in KSA, the "Informed Material" was braced the questionnaires from this paper aim; (Table 1) [6]. The "Coupled Assessment" was utilized for the content and study decency. The "Reaching Study Question Consequences" were amassed, then the "Moderate Excel Packet" was defined the outcome [7].

\begin{tabular}{|c|c|c|c|}
\hline \multirow[t]{2}{*}{ No. } & \multirow[t]{2}{*}{ Question } & \multicolumn{2}{|c|}{ Answer } \\
\hline & & Yes & No \\
\hline 1. & Perform regular daily ablution for prayer & & \\
\hline 2. & Urges an individuals to perform regular daily ablution & & \\
\hline 3. & Regular daily ablution helps to clean the body organs well & & \\
\hline 4. & Regular daily ablution is one of the ways to sterilize with running water & & \\
\hline 5. & Regular daily ablution is improved an individual health status & & \\
\hline 6. & Regular daily ablution helps to reduce an individual pathogenic microorganisms infection & & \\
\hline 7. & Regular daily ablution is one of the ways to protect an individual health from microbial diseases & & \\
\hline 8. & $\begin{array}{l}\text { Regular daily ablution helps the success of "Health Precautionary Measures" to prevent Coronavirus } \\
\text { infection }\end{array}$ & & \\
\hline 9. & Regular daily ablution health way to reduces an individuals Coronavirus infection & & \\
\hline 10. & Regular daily ablution healthy ways to reduce and protect Saudi society from Coronavirus infection & & \\
\hline
\end{tabular}

Table 1: Questionnaire for regular daily ablution (Wudu') consequence on reduction Coronavirus infection during pandemic in Saudi Society

\section{Results and Discussion}

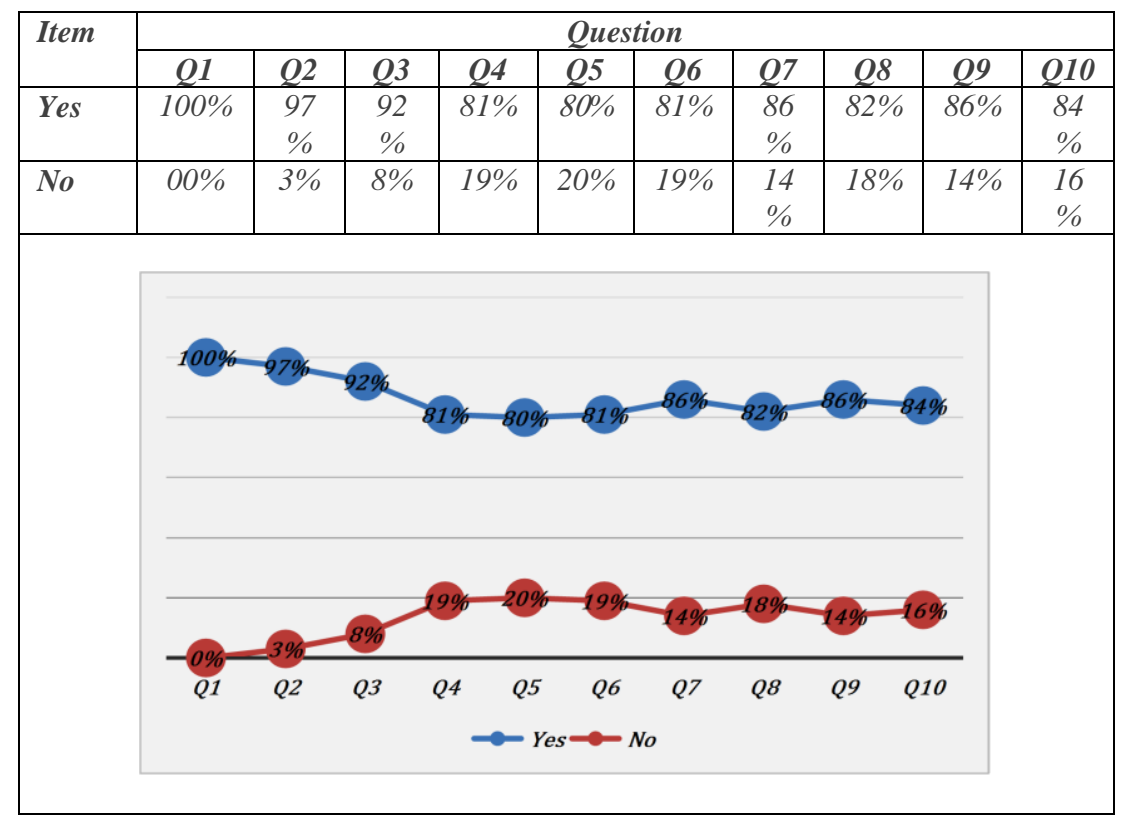

Table 2 and graph 1: Questionnaire results for regular daily ablution (Wudu') consequence on reduction Coronavirus infection during pandemic in Saudi Society

Table 2 and graph 1 conferred questionnaire results for regular daily ablution (Wudu') consequence on reduction Coronavirus infection during pandemic in Saudi Society, regular daily ablution (Wudu') is one of the basic steps for prayer and getting rid of the body secretions or any microbial contamination related to body organs [8]. The questionnaire was conducted in the Saudi Muslim community for the first time in KSA and that had the honor to perform that questionnaire on the Muslim brothers and sisters in the KSA holy country. The questionnaire was 
conducted for participants during the Coronavirus pandemic in KSA to estimate the value of regular daily ablution (Wudu') and its impact on health protection from infection for an individual and the Saudi society [9]. The first question was "Perform regular daily ablution for prayer"; it was $100 \%$ found that all an individuals participating in the questionnaire perform regular daily ablution (Wudu'). This is evidence of the strength of belief and Islam in an individuals [10]. As for the second question was "Urges an individuals to perform regular daily ablution"; it was $97 \%$ they urged an individuals to perform regular daily ablution (Wudu') or update ablution (Wudu') for prayer. It may 3\% be that not all of the participants go to mosques or be among the participating women who pray at home [2] The third question was "Regular daily ablution helps to clean the body organs well"; it was $92 \%$ clarifies and this confirms that almost all are less than $8 \%$ of the importance of cleaning through regular daily ablution (Wudu'), and it is a way to clean the body's organs during the process of regular daily ablution (Wudu') [1]. The fourth question was "Regular daily ablution is one of the ways to sterilize with running water"; that showed $81 \%$ of more than three-quarters of the participants, because the running water does not contain any of the materials used for sterilization, and their thinking may be more scientific than others, but running water is one of the good and useful cleaning materials [11]. The fifth question was "Regular daily ablution is improved an individual health status"; it was $80 \%$ approved by more than three quarters, as it purifies the organs that are used by an individual and is considered the entrance to the body organs of microbial infection. That such as the mouth, nose, eyes, face and ear. Also, regular daily ablution (Wudu') treats the extremities used to touch things and work, such as the hands to the elbows and feet. The regular daily ablution (Wudu') removes any pollutants that affect the health of an individual $[2-5,12]$. The sixth question was "Regular daily ablution helps to reduce an individual pathogenic microorganisms infection"; it was $81 \%$ soon everyone agreed, as a result of regular daily ablution (Wudu'), washing the organs three times for each member, repeating ablution (Wudu') five times per day, or updating ablution (Wudu'), as these include the entrances to the bodily devices and the bodily limbs used by the body as well. Thus, pollutants are reduced, the most important of which are pathogenic microbes or their source on the body of an individual $[2-5,13]$. The seventh question was "Regular daily ablution is one of the ways to protect an individual health from microbial diseases"; it was $86 \%$ stated that almost all of the participants in order to protect an individual from microbial diseases. The first step to protect against microbial diseases is to eliminate the source of pollution, clean the entrances to the bodily devices, and remove contamination from the bodily extremities. Regular daily ablution (Wudu') is one of the methods of ablution (Wudu') that helps to clean an individual and reduce the source of microbes that cause microbial diseases, and therefore it is one of the important ways for an individual to protect him from microbial diseases $[2-5,14]$. The eighth question was "Regular daily ablution helps the success of "Health Precautionary Measures" to prevent Coronavirus infection" it was $82 \%$ the percentage of approval among the participants was almost four-quarters, an that notice this during the Coronavirus pandemic from the cas an individuals. They frequently cleanse with disinfectants, washing and regular daily ablution (Wudu'). This is the biggest evidence of the importance of regular daily ablution (Wudu') from "Health Precautions" to reduce infection with the Coronavirus during the pandemic in KSA $[2-5,15]$. It was found from the ninth question was "Regular daily ablution health way to reduces an individual Coronavirus infection"; it was $86 \%$ resulted that more than three-quarters agreed, and this is the biggest evidence of reducing infection with the Coronavirus during the pandemic through the process of regular daily ablution (Wudu'). As it reduces pollution to organs and entrances to bodily devices such as the mouth, nose, eye and ear, which are the ways through which the Coronavirus may be transmitted and infection occurs for an individual $[2-5,16]$. The tenth question was "Regular daily ablution healthy ways to reduce and protect Saudi society from Coronavirus infection"; it was $84 \%$ proved that more than three-quarters of the participants agreed, and this is a follow-up to the ninth question, as the regular daily ablution (Wudu') of an individuals brings together the result of the Saudi society. This is because of the characteristics of Islam in the regularity of daily ablution (Wudu'), meeting in the mosque and listening to Islamic recommendations to protect the health of Saudi society from microbial diseases. As well as the Coronavirus during the pandemic in KSA [2-5, 17]. As well the regular daily ablution (Wudu') is one of the Islamic habits that helped reduce the infection of an individuals with infectious microbial diseases and also with the Coronavirus during the pandemic in Saudi society. This indicated the importance of regular daily ablution (Wudu') and updating ablution (Wudu') from God's commands for Muslim individual to protect health, and for an individual to stand for prayer while he does not suffer from any microbial diseases $[2-5,12 \&$ 17].

\section{Conclusion}

It was concluded that found through the results to the extent of the strength of Islam for the Saudi society and the strength of implementing the provisions of Islam for the individual and Saudi society. Regular daily ablution (Wudu') consequence had proven its ability to strengthen the health of the individual and the Saudi society and reduce infectious microbial diseases. Accordingly, the individual was one of the elements of Saudi society, and when observing regular daily ablution (Wudu') and updating ablution (Wudu') helped reduce and protect from Coronavirus infection during the pandemic. So this returns to Saudi society with results that were beneficial to individual health and the health of Saudi society.

\section{Recommendation}

It was recommend, that through the research, the commitment to implement the steps of Islam from the regular daily ablution (Wudu'), as it reduces the incidence of infectious microbial diseases and also reduces and protects individuals and Saudi society from infection with the Coronavirus during the pandemic.

\section{Acknowledgments}

Sent thanks to all persons whom reply questionnaire for assisting in the current research work.

\section{References}

1. Bajirova, M. (2018). Hygiene and health in Quran and Science. E. C. Gynaecology, 1, 44-55.

2. Khan, M., \& Yasir, M. (2020). Wudu (Ablution): An Effective Preventive Measure against Many Infectious Diseases. Research \& Reviews: A J. Unani, Siddha and Homeopathy, 7(3), 28-31.

3. Amin, J. (2020). Quarantine and hygienic practices about combating contagious disease like COVID-19 and Islamic perspective. J. Critical Reviews, 7(13), 3697-3705.

4. Yanti, B., Maulana, I., Sofiana, D., Sufani, L., \& Jannah, N. (2021). Nasal rinse and gargling as an effort in preventing COVID-19 infection with Islamic approach-a literature review. Bali Medical Journal (Bali Med. J.), 10(2), 503-506.

5. Saefulloh, A., Famularsih, S., Syarif, M., Adimarta, T., \& Helmy, I. (2021). Covid-19 Prevention (Study of Covid-19 Protocol and Relationship of Wudhu). The J. Society and Media, 5(1), 99-118.

6. Jirwe, M., Gerrish, K., Keeney, S., \& Emami, A. (2009). Identifying the core components of cultural competence: findings from a Delphi study. J. of clinical nursing, 18(18), 2622-2634.

7. Purwanto, A., Santoso, B., Siswanto, E., Hartuti, H., Setiana, N., Sudargini, Y., \& Fahmi, K. (2021). Effect of Hard Skills, Soft Skills, Organizational Learning and Innovation Capability on 
Islamic University Lecturers' Performance. Int. J. Social and Management Studies, 2(1), 14-40.

8. Nasir, M. (2017). Exploring the health information needs of pilgrims for the protection against infectious diseases during mass muslim gatherings (HAJJ), (Doctoral dissertation).

9. Abideen, U., \& Abbas, F. (2021). Believers, Islamic Brotherhood and Mosque-Based Emotional and Informal Social Support System among Muslims in Pakistan. J. Religion, Spirituality \& aging, 33(1), 54-85.

10. Khan, A. (2021). Poems to Shauki Masi: Diasporic Queer South Asian Muslim Reflections on the Five Pillars of Islam. Meridians, 20(1), 183-192.

11. Tao, M., Ao, T., Mao, X., Yan, X., Javed, R., Hou, W., \& Yu, T. (2021). Sterilization and disinfection methods for decellularized matrix materials: Review, consideration and proposal. Bioactive Materials, 6(9), 2927-2945.

12. Sabra, S. (2018). Ablution (Wudu) Health Benefits (HBs) through Comparison Nasal-Cavity (NC) Bacterial-Content (BC) with Gold-Standard (GS) at High-Altitude (HA) Area, Taif, KSA. J. App. Biotechnology \& Bioengineering, 5(6), 334-
336.

13. Ramli, R., Mohamad, I., Ab Wahab, S., Naing, N., \& Din, W. (2018). A pilot study on the efficacy of nasal rinsing during ablution in reducing acute respiratory tract infection (ARI) among male Hajj pilgrims. J. Taibah University medical sciences, 13(4), 364-369.

14. Hellman, S., Chen, G. H., \& Irie, T. (2020). Rapid clearing of aerosol in an intubation box by vacuum filtration. British $J$. Anaesthesia, 125(3), e296-e299.

15. Utunen, H., Van Kerkhove, D., Tokar, A., O'Connell, G., Gamhewage, M., \& Fall, S. (2021). One Year of Pandemic Learning Response: Benefits of Massive Online Delivery of the World Health Organization's Technical Guidance. JMIR Public Health and Surveillance, 7(4), e28945-e28949.

16. Ciaranello, A., \& Bell, T. (2021). Using Data and Modeling to Understand the Risks of In-Person Education. JAMA Network Open, 4(3), e214619-e214619.

17. Sabra, S. (2021). Influence of Applying Preventive Health Conditions Strategy during Coronavirus Pandemic in KSA. J. Biotech. and Bioprocessing, 2(1).-014.
This work is licensed under Creative Commons Attribution 4.0 License

To Submit Your Article Click Here: Submit Manuscript

DOI: $10.31579 / 2690-8808 / 089$
Ready to submit your research? Choose Auctores and benefit from:

* fast, convenient online submission

* rigorous peer review by experienced research in your field

* rapid publication on acceptance

* authors retain copyrights

* unique DOl for all articles

* immediate, unrestricted online access

At Auctores, research is always in progress.

Learn more https://auctoresonline.org/journals/journal-of-clinical-casereports-and-studies 